\title{
REALIDADE EDUCACIONAL DAS ESCOLAS RURAIS DO MUNICÍPIO DE JATAÍ - GO
}

\author{
LEAL, Cátia Regina Assis Almeida. UFG/CAJ. catiaassisleal@gmail.com \\ SILVA, João Paulo dos Santos. UFG/CAJ. jped.fisica@hotmail.com \\ CARVALHO, Tatielle Goulart. UFG/CAJ. tatiskovt@gmail.com
}

\begin{abstract}
RESUMO: Objetiva-se por meio do presente texto elucidar a realidade educacional das escolas localizadas na área rural do município da Jataí - GO. Entende-se que a organização das escolas deve pautar-se nos interesses e anseios da população que ela atende. Com isso, as escolas que atendem a população camponesa devem ser organizadas, no que se refere à seleção de conteúdos, didática e proposta pedagógica, de acordo com a realidade camponesa. Nesta perspectiva, se o trabalho com a terra e com os animais é uma realidade para a população que vive em área rural, nada mais lógico que as escolas ali localizadas trabalhem os conteúdos das disciplinas português e matemática, entre outras, mas que também abordem conteúdos agronômicos, zootécnicos e veterinários. Além das disciplinas técnicas da ciência da terra, alguns conteúdos relativos à sociologia rural devem também ser abordados nessas escolas, permitindo assim que o camponês possa conhecer e refletir sobre a história de luta das populações camponesas. Os estudos de Silva (2010) e Leal e Carvalho (2009) indicam que as escolas que atendem a população camponesa no município Jataiense são escolas citadinas inseridas no meio rural. Segundo esses autores a escola localizada no campo em Jataí, segue o mesmo modelo de organização das escolas da cidade, desconsiderando assim as peculiaridades da vida do camponês. Outra consideração que pode ser feita sobre a organização dessas escolas é a respeito das suas gestões. Até no ano de 2008, a Secretaria Municipal de Educação (SME) administrava todas as escolas no campo, porém, a partir de 2009 essas escolas passaram a ser geridas por meio da gestão compartilhada entre a (SME) e a Secretaria Estadual de Educação (SEE). No decorrer do texto os detalhes do convênio da gestão compartilhada serão apontados de forma mais pontual.
\end{abstract}

\section{Palavras-chave: Educação Rural, Escola, Jataí.}

ABSTRACT: This text aims at debating the educational reality of the rural based schools in the town of Jataí, state of Goiás, Brazil. It is of general understanding that their organization must be anchored on the interests and aspirations of the people they serve, who must be taken into account in the definition of the schools' teaching contents and methods and pedagogical proposal. Since working with the land and animals is a reality for the population who live in rural areas, nothing more logical than for the schools to impart the disciplines of Portuguese and Mathematics along with agronomical, zootechny and veterinarian contents. Besides technical courses related to the earth sciences, subjects related to rural sociology must also be introduced in these schools, allowing the countrymen to know and reflect upon the history of struggle of the rural populations. The studies by Silva (2010) and Leal and Carvalho (2009) reveal that the rural schools of Jataí are urban based, despite being inserted in the rural region. According to the authors, such schools follow the same model of organization of those in the urban area, disregarding the peculiarities of the peasants' lifestyles. The schools' management is also called upon attention. Until 2008, the town's Department of Education administered all the schools in the rural area, but since 2009 they have been run by a joint management system between the town's and the state's Departments of Education. Throughout the text, details of this agreement will be pointed out. 


\title{
Keywords: Rural Education School, Jataí. INTRODUÇÃO
}

\begin{abstract}
A violência dos opressores, que os faz também desumanizados, instaura uma outra vocação - a do ser menos. Como distorção do ser mais, o ser menos leva os oprimidos, cedo ou tarde, a lutar contra quem os fez menos. E esta luta somente tem sentido quando os oprimidos, ao buscarem recuperar a sua humanidade, que é uma forma de criá-la, não se sentem idealistamente opressores, mas restauradores da humanidade em ambos. (FREIRE, 1987. p. 30)
\end{abstract}

O trecho destacado acima que dá início ao nosso texto é um fragmento retirado do clássico livro de Paulo Freire "Pedagogia do Oprimido”. Esta obra a décadas é referência para muitos educadores que consideram que a prática pedagógica deve ir além da preparação para o mundo do trabalho. Esses educadores consideram que a educação deve ser um instrumento nas mãos da população que é oprimida em nossa sociedade, na busca pela sua libertação.

Pelo fato de viver em uma sociedade democrática, como é a brasileira, em que os seus cidadãos podem exercer o seu direito de ir e vir e de expressar, a maioria das pessoas se considera também detentores de sua liberdade. Porém, elas se esquecem que vivem em uma sociedade em que a maioria da população é oprimida por uma minoria.

A opressão que é falada por Freire (1987), refere-se à estrutura da nossa sociedade que está organizada em classes. Os detentores do poder político e econômico são os opressores, e o povo, que tem apenas a sua força de trabalho são considerados os oprimidos. Os opressores oprimem os oprimidos ao passo que eles se utilizam do seu poder para acumular as riquezas que são produzidas na sociedade e perpassar a idéia de que o mundo é o quê é, e assim o será eternamente, relegando aos oprimidos apenas o direito de sobreviver. Os opressores em nossa sociedade conseguem, às custa dos oprimidos, o direito de ter uma vida confortável e luxuosa, enquanto os oprimidos vivem em condições de vida precária.

A liberdade que é pensada por Freire (1987) não se resume somente aos direitos de ir e vir e expressar as idéias. A liberdade que é pensada refere-se ao direito de ter uma moradia confortável, uma alimentação saudável, a saúde, a escolarização, ou seja, a liberdade de ter uma vida digna e usufruir também das riquezas que são produzidas pela sociedade.

Tendo a liberdade nesta ótica, Freire (1987) diz que a educação é considerada como um meio de luta para a população oprimida da sociedade se libertar da opressão em que está sujeita. Neste texto vislumbramos educação da mesma forma que é apresentada por Paulo freire. Consideramos aqui, que a educação deve estar pautada em princípios que permita que as pessoas façam uma leitura crítica da sociedade em que vivem. A partir do momento em que 
os indivíduos se tornem críticos, eles podem lutar pela transformação. Pois, ao contrário do que diz os ideais forjados nos valores das classes dominantes, a sociedade pode ser transformada e as pessoas podem ter uma vida digna. Ou seja, as pessoas podem lutar por aquilo que Paulo Freire chama de "humanização" da sociedade em que vivem.

A escolha do trecho que dá início ao nosso texto não foi feita ao acaso, pois, consideramos que há uma estreita relação entre o que é dito por Freire (1987) e o assunto que trataremos aqui. Em nosso texto, a educação, é tratada da mesma forma, como instrumento de formação de um homem crítico, questionador e interventor na sociedade em que vive. Assim como Freire (1987) trataremos em nosso texto sobre a educação com vistas a humanização, pois, acreditamos também que a educação não deve estar pautada no utilitarismo da formação de mão-de-obra e sim na formação de cidadãos capazes de lutar pelos seus direitos e exercer a sua cidadania.

Da mesma forma que Freire (1987) considera que a luta dos oprimidos contra os opressores, deve significar não a opressão dos que oprimiam e sim a humanização dos dois grupos, assim pensamos. Com isso, queremos que a educação seja pautada em princípios que permitam a luta por melhores condições de vida dos oprimidos. Uma educação que permita aos indivíduos analisarem criticamente a sociedade em que vivem na busca pela transformação.

\section{Relação campo-cidade}

O trecho retirado de Freire (1987) foi escolhido para encabeçar este texto, pois, trataremos daqui em diante, da educação de uma parcela da sociedade que a décadas vem sendo oprimida: as populações que vivem em áreas rurais. Para demonstrar essa opressão, falaremos um pouco sobre a forma hegemônica de como o campo é visto em nossa sociedade. Em seguida apresentaremos uma forma contra-hegemônica de se perspectivar o rural.

Na lógica hegemônica o campo é tido como tudo aquilo que "sobra” da cidade, nesta perspectiva, delimita-se os limites geográficos entre o campo e cidade por meio de uma metodologia implementada pelo Instituto Brasileiro de Geografia e Estatística (IBGE) que é utilizada desde o ano de 1938, que considera urbano toda a aglomeração municipalizada. (Pessoa, 2007). Para esse autor, 
as atividades econômicas, atraindo as populações rurais e, quando isso não acontece, subjugando as mercadorias da sua produção artesanal e doméstica; e ainda caracterizando como subcultura o modo de vestir, de falar e de pensar da gente do meio rural. (p. 26)

Nesta perspectiva, o campo é visto como sinônimo do atraso em contraste com a modernidade do seu oposto, a cidade.

O campo também é tido como o local onde mora o caipira que tem como característica ser atrasado, ridículo e engraçado. Na visão hegemônica o modo de vida das pessoas que vivem no campo não tem lugar na sociedade moderna em que vivemos, sendo assim nada mais que normal o seu desaparecimento. Segundo Oliveira (2004) essa forma de ver o campo tem se constituído como um paradigma social chamado de "inevitável fim do rural”, e se acaso ele se perpetuar, daqui a algum tempo não existirão mais pessoas morando em áreas rurais, e o modo de vida rural será extinto.

Se acaso esse paradigma seja perpetuado, as áreas rurais serão no futuro apenas o local do maquinário agrícola sofisticado e das grandes propriedades capitalistas. As populações que hoje moram no campo, nesta visão, terão como única forma de sobrevivência, a migração para as cidades.

Porém, se contrapondo a essa visão hegemônica que tem resultado na não permanência de pessoas residindo no campo, apresentaremos a visão contra-hegemônica na qual somos partidários. Uma forma de entender o campo que chamaremos aqui de “conservação do rural”.

Essa visão de conservação do rural, não considera a demarcação dos limites geográficos como a forma mais coerente de se delimitar o campo e a cidade. Para nós a fronteira campo-cidade apresenta-se, hoje, de forma tênue, pois, não se pode dizer com certeza, onde está o campo e nem onde está a cidade. Entendemos que,

[...] é mais seguro falar do rural levando em conta três considerações: a) o rural não mais ou não apenas como categoria geográfica específica; b) o rural não mais ou não apenas como produção agrícola ou agropecuária; c) o rural como representação social e simbólica. Explicando um pouco melhor essa terceira dimensão, pode-se dizer que o rural, independente de onde se mora ou o que se faz, é uma concepção de mundo, um modo como as pessoas e os grupos organizam suas relações sociais e produtivas. (PESSOA, 2007, p.16)

Nesta perspectiva, não se pode simplesmente demarcar os limites geográficos entre o rural e o urbano, da mesma forma que as áreas rurais não podem ser consideradas apenas, como locais da agropecuária em longa escala. 
Segundo Pessoa (2007), atualmente existe uma grande parcela da população brasileira que vive em áreas rurais, esses camponeses são dependentes de muitos recursos que são encontrados apenas na cidade, como serviços de saúde e comércio. Da mesma forma que um grande contingente populacional urbano, é oriundo de áreas rurais, sendo assim, muito mais ligados à cultura rural do que a cultura urbana.

Esta inter-relação entre campo e cidade é chamada por alguns estudiosos da sociologia rural como o fenômeno das ruralidades. Carneiro citada por Pessoa (2007) incrementando o debate sobre a ruralidade, diz que,

[...] não podemos entender a ruralidade hoje somente a partir da penetração do mundo urbano-industrial no que era definido tradicionalmente como "rural", mas também do consumo pela sociedade urbano-industrial, de bens simbólicos e materiais (a natureza como valor e os produtos "naturais", por exemplo) e de práticas culturais que são reconhecidos como sendo próprias do chamado mundo rural. Nesse sentido, importa mais do que tentarmos redefinir as fronteiras entre 0 "rural" e o "urbano", ou simplesmente ignorar as diferenças contidas nessas representações sociais, os significados das práticas sociais que operacionalizam essa integração e que proliferam tanto no campo como nos grandes centros urbanos. (p. 17)

Assim como o exposto no parágrafo acima, consideramos que o mais importante do que delimitar limites geográficos é o entendimento de formas viáveis de manutenção do "rural” e do "urbano".

Nesta lógica, considera-se que para a conservação do rural é importante que existam pessoas morando no campo. Nosso entendimento é o de que, o campo, não é apenas o local do latifúndio e do agronegócio. As áreas rurais são também no nosso entendimento o local da agricultura familiar e da pequena propriedade.

No nosso entendimento a população que reside no campo não é o caipira atrasado, muito pelo contrário, atrasada é essa forma de ver o camponês. Ao pensarmos no camponês não podemos mais cometer o erro de achar que quem mora no campo são aquelas pessoas totalmente alheias à tecnologia da cidade que trabalham na enxada e que moram em casas de pau-a-pique.

O homem do campo tem algumas diferenças com o homem da cidade, e isso não pode ser negado, como por exemplo, desde a mais tenra idade ele é um trabalhador (LEAL e CARVALHO, 2009). Ele também é senhor do seu tempo, é ele quem organiza os seus próprios horários de trabalho. 
Porém, nas atuais relações campo-cidade, o homem que mora no campo também se mostra com muitas semelhanças com o homem da cidade. Ele também quer ter uma casa confortável. Ele quer ter acesso às tecnologias que são produzidas pela sociedade, e que tanto facilitam a vida das pessoas. Ou seja, o homem do campo luta contra a opressão que lhe é imposta, ele luta pela reprodução da sua campesinidade e por uma vida digna, e o que é mais importante, ele luta pela sua permanência no campo.

\section{Educação para regiões e populações rurais}

No processo de perpetuação do paradigma da conservação do rural, a educação é para nós um instrumento essencial. Consideramos a educação como uma forma de munir o camponês de recursos na luta contra a opressão. Nesta perspectiva entendemos que as escolas que fazem o atendimento ao campesinato, para serem consideradas realmente rurais, não pode se organizar de forma alheia a realidade camponesa. As escolas rurais devem ser organizadas de acordo com os interesses dessa população. Ou seja,

[...] é preciso que as comunidades locais, os agentes educacionais a elas ligados, enfim, todas as pessoas e grupos interessados estudem as modalidades de organização escolar existes, as experiências em andamento e busquem formas de adequação da educação à realidade e os anseios das populações rurais[...]. (PESSOA, 1997, p. 155)

Quando nos referimos à escola rural organizada conforme os "interesses dessa população”, estamos querendo dizer que os conteúdos e as práticas pedagógicas das escolas rurais devem ser organizados dentro dos assuntos inerentes a realidade camponesa. Por exemplo, se o homem do campo lida com a terra, nada mais lógico que na escola dos seus filhos, além dos conteúdos como português e matemática, sejam também abordados conteúdos agronômicos. Da mesma forma que acreditamos que conceitos zootécnicos e veterinários devam aparecer entre os conteúdos, pois, lidar com animais é uma realidade na vida dessas pessoas.

Além de considerar importante a abordagem de conteúdos técnicos das ciências da terra, também defendemos a introdução de conteúdos relacionados a conhecimentos da sociologia rural nessas escolas. Esses conteúdos são por nós considerados importantes, pelo 
fato de que é por meio do conhecimento e da reflexão sobre a história de luta camponesa que o camponês pode se fortalecer na luta pela sua permanência no campo.

Tendo como eixo norteador esta perspectiva de organização de escola rural que apresentamos nos últimos parágrafos, será apresentada a seguir um estudo sobre a realidade educacional das escolas localizadas na área rural do município de Jataí - GO.

A importância desse trabalho reside no fato de que no meio acadêmico pouco conhecimento tem sido construído sobre essa temática. Se compararmos a quantidade de produção acadêmica com o número de pesquisas relacionadas ao meio rural, nota-se que pouco tem se pensado na educação camponesa. (OLIVEIRA, 2004)

Segundo Pessoa (2007) nas últimas décadas, houve um significativo avanço nos debates que dizem respeito à educação camponesa. No entanto, esse avanço não se materializou quantitativamente em estudos sobre a realidade educacional das escolas rurais. “[...] pensar uma escola localizada no campo não esgota a problemática do atendimento educacional das populações rurais.” (p. 14)

Para falar da realidade das escolas que atendem a população rural em Jataí, seguiremos a seguinte lógica. Primeiramente, vamos falar sobre a realidade do município no que se refere à localização geográfica e estrutura agrária. Em seguida, faremos a demonstração de alguns dados que fazem um mapeamento sobre o número de escolas, a quantidade de alunos por elas atendidos e os níveis de ensino que são ofertados. Em seguida, discutiremos sobre a organização dessas escolas.

Para finalizar, iremos falar um pouco sobre a gestão dessas escolas, pois, na atualidade elas são geridas pelo convênio da gestão compartilhada entre a (SME) e (SEE).

\section{Jataí: localização geográfica e estrutura agrária}

O município de Jataí está localizado na região Sudoeste do Estado de Goiás, aproximadamente 320 da capital, Goiânia. A região Sudoeste de Goiás é conhecida pelo seu grande crescimento advindo do agronegócio. Figura entre os municípios dessa região que mais tem crescido com a produção agrícola. Segundo os dados do IBGE (2010) o município Jataiense está entre os dez maiores produtores de soja do país e a sua produção de milho safrinha é uma das maiores do Brasil.

Outra característica desse município, que é considerada por nós importante para o nosso texto, e por isso será ressaltada, é a sua estrutura agrária. Segundo Dias (2008) as 
pequenas propriedades de Jataí somam apenas 2,5\% do total do território do município. Ou seja, Jataí é um local em que a estrutura sócio-agrária é marcada pela presença do latifúndio. Gomes citado por Oliveira (2004) diz que, “[...] historicamente o sudoeste goiano sempre se caracterizou como região de domínio da grande propriedade.” (p. 44).

Se historicamente no município Jataiense a ocupação da terra ocorreu por meio das grandes propriedades, isso explica o motivo pelo qual o latifúndio ocupa na atualidade 97,5 \% do território. Mesmo o município tendo passado pelo processo de modernização agrícola a estrutura agrária não sofreu transformações, pois, ”a agricultura brasileira sofreu um profundo processo de transformação tecnológico, sem que se tenha ocorrido qualquer modificação da estrutura agrária, conservando e agravando o padrão injusto de distribuição da posse das terras.” (LEAL, 2006, p. 39-40).

Como já foi dito, uma escola para ser considerada rural deve ter como foco de sua organização, as peculiaridades locais da população que ela atende. Uma escola rural é de interesse da população que vive no campo e realmente estuda nesta escola. As pessoas que utilizam das escolas localizadas no campo são os filhos dos pequenos proprietários de terras, dos trabalhados assentados, entre outros, que realmente moram na terra e que lutam para dar uma vida digna para sua família. Ou seja, uma escola rural interessa para o camponês que vê a terra como fonte da reprodução da vida e não com fonte de acumulação de riquezas, é essa população que forma o campesinato Jataiense, a outra parcela da população rural é formada pelos empresários capitalistas. Porém, o campesinato não detém o poder político e econômico do município, muito pelo contrário, ele ocupa uma pequena parcela do território. (DIAS, 2008)

Na lógica do capital, em que o importante é o lucro, o que traz o crescimento para o município é o agronegócio. O agronegócio tem como principal objetivo tirar da terra a máxima produção possível, com isso é importante que se tenha a cada dia, maiores áreas para serem exploradas. Nesta lógica, não é de interesse para o agronegócio que existam pessoas morando no campo, pois, quanto menos pessoas viverem no campo, maior será a área para se explorar e acumular capital. Ou seja, organizar uma escola rural que sirva aos interesses das populações que vivem no campo vai contra os interesses do agronegócio.

Alguns estudos, como o de Leal (2006) e Oliveira (2004), apontam que não estão introjetado no campesinato Jataiense, os ideais de transformação pela via dos movimentos sociais. O campesinato em Jataí, “está mais voltado às políticas de integração do capital. 
Portanto, aquele traço revolucionário do campesinato [...] não é um dado presente em Jataí.” (OLIVEIRA, 2004, p. 55).

A não presença dos movimentos sociais no município faz com que a luta para permanecer na terra não seja também a luta pela escola rural. Com isso, pode-se dizer que o campesinato não tem considerado a educação dos seus filhos, como uma forma de auxilio na luta para se permanecer na terra.

É importante que se fale sobre a estrutura-agrária, pois esta, influência muito na organização da escola rural. Isso é dito pelo fato de que Jataí é um local que se caracteriza pelo latifúndio, e o latifúndio tem como principal atividade econômica o agronegócio, e para o agronegócio não é importante uma escola rural. A escola rural é importante para o campesinato, porém, este, tem se preocupado mais com agir na lógica da reprodução do capital, e não tem pensado na organização das escolas que atendem seus filhos.

\section{Escolas rurais no município de Jataí}

Por meio de dados disponibilizados pela Secretaria Municipal de Educação (SME), até o segundo período do ano letivo de 2010, estavam matriculados nas escolas da área rural aproximadamente 1.416 alunos. Esses alunos estão divididos em oito escolas, sendo elas: Escola Clobertino Naves da Cunha, Escola Romulda de Barros, Escola Campos Elísios, Escola Professora Maria Zaiden, Escola Nilo Lottici, Escola Professor Chiquinho, Escola Rio Paraíso III e Escola Boa Vista.

A tabela abaixo demonstra a distribuição do número de alunos por escola e por nível de ensino no segundo semestre letivo de 2010.

Tabela 1: Alunos matriculados nas escolas rurais em agosto de 2010.

\begin{tabular}{|c|c|c|c|c|c|}
\hline Escolas Rurais & $\begin{array}{c}\text { Educação } \\
\text { infantil }\end{array}$ & $\begin{array}{c}1^{\circ} \text { fase do ensino } \\
\text { fundamental }\end{array}$ & $\begin{array}{c}2^{\circ} \text { fase do ensino } \\
\text { fundamental }\end{array}$ & $\begin{array}{c}\text { Ensino } \\
\text { médio }\end{array}$ & Total \\
\hline $\begin{array}{c}\text { Clobertino } \\
\text { naves da } \\
\text { Cunha }^{1}\end{array}$ & 19 & 163 & 110 & - & 292 \\
\hline $\begin{array}{c}\text { Romualda de } \\
\text { Barros }\end{array}$ & 21 & 111 & 68 & 48 & 248 \\
\hline $\begin{array}{c}\text { Campos } \\
\text { Elísios }\end{array}$ & 7 & 84 & 59 & 22 & 172 \\
\hline
\end{tabular}

1. As escolas Clobertino Naves da Cunha e Romualda de Barros estão situadas em regiões rurais, porém urbanizadas, consideradas distritos de Jataí (Povoados). 


\begin{tabular}{|c|c|c|c|c|c|}
\hline $\begin{array}{c}\text { Professora } \\
\text { Maria Zaiden }\end{array}$ & 12 & 62 & 50 & 33 & 157 \\
\hline Nilo Lottici & 7 & 80 & - & - & 87 \\
\hline $\begin{array}{c}\text { Professor } \\
\text { Chiquinho, }\end{array}$ & 8 & 70 & 50 & 25 & 153 \\
\hline Rio Paraíso III & 9 & 63 & 56 & 43 & 171 \\
\hline Boa Vista & 3 & 68 & 48 & 17 & 136 \\
\hline Total & 86 & 701 & 441 & 188 & 1416 \\
\hline
\end{tabular}

FONTE: Secretaria Municipal de Educação, 2010.

De acordo com a tabela 1, as escolas localizadas em áreas rurais em Jataí, atendem a população camponesa em todos os níveis de ensino da educação básica (Educação infantil, ensino fundamental e ensino médio). Por nível de ensino, 86 alunos estão matriculados na educação infantil, 701 estão matriculados na $1^{\circ}$ fase do ensino fundamental, 441 matriculados na $2^{\circ}$ fase do ensino fundamental e 188 matriculados no ensino médio.

Sobre a organização dessas escolas, existem alguns estudos acadêmicos bem recentes, dos quais podemos citar Silva et. al. (2010) e Leal e Carvalho (2009). Segundo os autores mencionados, essas escolas no que se refere a sua organização (planejamento didático-pedagógica, seleção de conteúdos etc.) são pensadas a partir do modelo de escola da cidade.

Silva et. al. (2010) diz que,

\begin{abstract}
Os dados indicam que os currículos das escolas rurais do município de Jataí são organizados conforme a realidade das escolas urbanas, fazendo com que os conhecimentos passados pela escola não estejam de acordo com a vida e com os interesses do camponês. Fica evidente que os currículos dessas escolas devem ser repensados e organizados de forma que os conteúdos permitam uma didática coerente à realidade de cada escola. Só assim a escola poderá contribuir com as necessidades e anseios dos camponeses. (p. 7)
\end{abstract}

Leal e Carvalho (2010), também ressaltam esta desarmonia entre o que é ensinado na escola e a realidade dos camponeses. Segundo essas autoras o planejamento pedagógico em Jataí, “acontece todo início de ano letivo com a participação de todos os professores da rede pública que trabalham na área, os conteúdos a serem aplicados são pensados da forma geral e utilizados tanto para escola urbana quanto para a escola rural” (LEAL e CARVALHO. 2009, p. 6-7)

Os dois estudos indicam que as escolas rurais no município de Jataí, são escolas citadinas inseridas no meio rural, pois, seguem a mesma proposta pedagógica e ordenação dos 
conteúdos das escolas da cidade. Esses estudos são muito relevantes para se mostrar a realidade educacional das escolas rurais em Jataí, pelo fato de serem muito atuais. Datam dos anos de 2009 e 2010, e indicam que as escolas localizadas no campo Jataiense são organizadas usando a mesma lógica da cidade. Pela proximidade desses estudos com o atual ano de 2011, infere-se que esta situação dificilmente tenha se alterado.

\section{Gestão compartilhada nas escolas rurais}

Até o ano de 2008 a gestão das escolas rurais do município de Jataí estava a cargo apenas da SME, porém, a partir do ano 2009, foi feito um convênio de gestão compartilhada entre SME e a SEE. Este convênio está pautado na Lei n 9.394/1996, Lei de Diretrizes e Bases da Educação (LDB). Segundo LDB (BRASIL, 1996) as três esferas administrativas (União, Estados e Municípios), devem ter autonomia para organizar seus sistemas ensino.

Os sistemas de ensino municipais e estaduais têm a obrigação de ofertar vagas gratuitas para a população em determinados níveis de ensino da educação básica, ficando o ensino superior e técnico sob a responsabilidade da União. A educação básica está dividida em três níveis de ensino: educação infantil, ensino fundamental e ensino médio. Existe também uma subdivisão no ensino fundamental: primeira fase $\left(1^{\circ}\right.$ ao $5^{\circ}$ ano $)$ e segunda fase $\left(6^{\circ}\right.$ ao $9^{\circ}$ ano $)$.

Quanto à obrigação de ofertas de vagas, os Sistemas Municipais de Educação devem ofertar vagas na educação infantil e primeira fase do ensino fundamental, e o Sistema Estadual deve ofertar vagas a partir da segunda fase do ensino fundamental até o final do ensino médio. Ou seja, o sistema municipal de ensino de Jataí, ao gerir toda a educação rural no município estava ofertando vagas que não eram de sua alçada, pois, ele ofertava vagas da segunda fase do ensino fundamental e ensino médio.

Com isso o sistema municipal de educação, a partir de 2009, amparado pela legislação deixou de se responsabilizar pela oferta de vagas para a segunda fase do ensino fundamental e ensino médio para as escolas rurais. Para cumprir com a sua obrigação legal o sistema estadual teve que ofertar essas vagas, como o Estado não possuía nenhuma estrutura física na área rural Jataiense, foi feito o convênio da gestão compartilhada.

O convênio da gestão compartilhada foi uma solução emergencial para o problema da oferta de vagas nas escolas rurais, pois, o Sistema Estadual de Educação tinha à 
obrigação de ofertar as vagas. Esse convênio resultou em um contrato em que o Município e o Estado tinham que cumprir as suas obrigações. Competiu ao Município emprestar a estrutura física, custear os gastos com os professores da educação infantil e $1^{\circ}$ fase do ensino fundamental e pagar 50\% dos gastos com o funcionamento das escolas (transporte de professores, faxineiros, guardas, merenda escolar etc.). Em contrapartida o Estado assumiu a obrigação de custear $50 \%$ dos gastos com o funcionamento das escolas e o salário dos professores da $2^{\circ}$ fase do ensino fundamental e do ensino médio.

A partir deste contrato da gestão compartilhada, a gestão das escolas rurais em Jataí ficou da seguinte forma. Em 6 das 8 escolas localizadas no campo, o governo estadual assumiu a segunda fase do ensino fundamental e o ensino médio, essas escolas foram: Professor Chiquinho, Boa vista, Campos Elízios, Romualda de Barros, Maria Zaiden e Rio Paraíso III.

Nas outras duas escolas, Nillo Lottici e Clobertino Naves da Cunha este processo não foi o mesmo. Na Escola Nillo Lottici pelo fato dela só ofertar vagas para o ensino infantil e $1^{\circ}$ fase do ensino fundamental, permaneceu como responsabilidade do município. Já na Escola Clobertino Naves o Estado assumiu apenas o ensino médio. Dados fornecidos pela SME, indicam que a escola Clobertino Naves tinha um grande contingente de professores concursados pelo município, se o Estado assumisse também a segunda fase do ensino fundamental, esses professores não conseguiriam cumprir as suas cargas horárias e teriam que ser demitidos. Para não ter que demitir os professores, a SME e a SEE entraram em um consenso, e decidiram que a melhor solução seria que o Estado assumisse apenas o ensino médio.

Outro dado que não pode ser desprezado é a estrutura administrativa dessas escolas. A parcela dos alunos que ficou sob a responsabilidade da SME continuou a ser administrada pelos gestores (diretores e vice-diretores) que já trabalhavam nessas escolas. Já a parcela dos alunos de responsabilidade do Estado, passou a ser administrados pelo diretor e vice-diretor do Colégio Estadual José Feliciano Ferreira situado em área urbana. Isso se deu pelo fato do contrato de gestão partilhada ter sido uma medida emergencial, transformando as escolas do campo numa extensão da escola da cidade. Ou seja, os níveis de ensino geridos pelo Estado.

Pelo fato da gestão compartilhada ter sido uma medida emergencial, não houve tempo para SEE organizar uma estrutura administrativa para cada uma das escolas. A solução 
encontrada foi transformar a parcela das escolas administradas pelo Estado em extensões rurais, administrados pelo diretor e vice-diretor do Colégio Estadual José Feliciano Ferreira situado em área urbana.

As extensões acontecem da seguinte forma, os gestores do Colégio Estadual José Feliciano Ferreira gerem também a parcela de responsabilidade do Estado nas escolas rurais. Eles mantêm em cada uma das extensões um coordenador pedagógico sobre suas orientações e coordenam cada uma das escolas de forma itinerante, seguindo o Plano Político Pedagógico (PPP) da escola citadina.

A gestão compartilhada é um assunto muito recente no meio acadêmico brasileiro, isso faz com que não se tenha um número muito expressivo de estudos a esse respeito. Em Jataí, a situação é a mesma, a gestão compartilhada foi implantada há apenas dois anos, e por esse curto período de tempo desde sua implantação, só existe até o presente momento, um estudo dedicado a esta temática ${ }^{2}$.

Souza (2009) era diretora do Colégio José Feliciano Ferreira e participou de todo o processo de implantação da gestão compartilhada no município. Em sua pesquisa ela trata de forma bem clara e detalhada de que forma se deu todo este processo; descreve sobre as reuniões que aconteceram, os problemas que foram aparecendo no decorrer dos debates, o número de pessoas que participaram de todas as reuniões, entre outros detalhes. No entanto, nessa pesquisa, em nenhum momento é citado pela autora, que esteve entre as preocupações dos debates, as peculiaridades da vida camponesa.

Isso pode significar que as pessoas que gerem as escolas localizada no campo em Jataí, perspectivam a organização da escola rural da mesma forma que da escola urbana, desconsiderando assim, os anseios e interesses da população camponesa que já foram apontados anteriormente neste texto.

Percebe-se no estudo de Souza (2009) que a implantação da gestão compartilhada devido seu caráter emergencial, foi um processo muito atribulado, em que esses gestores tiveram que resolver muitos problemas, como contratar professores, resolver algumas pendências relativas ao transporte dos professores, entre outras pendências, em um curto período de tempo, pois, já se iniciava o ano letivo de 2009 e as vagas tinham que ser

\footnotetext{
${ }^{2} \mathrm{O}$ único estudo realizado até a atualidade sobre a gestão compartilhada no município de Jataí é o trabalho de conclusão de curso (TCC) feito por Souza (2009). Este TCC foi apresentado à Faculdade de Educação da Universidade Federal de Goiás como requisito ao título de Especialista em Gestão Escolar, do Programa Nacional de Gestores da Educação Básica/MEC.
} 
ofertadas. Com isso, não se pode dizer que as peculiaridades camponesas foram simplesmente esquecidas nos debates da gestão compartilhada. O que pode ser dito é que em Jataí as escolas rurais sempre foram organizadas tendo como parâmetro a escolas da cidade. E da forma que se deu o processo de implantação da gestão compartilhada, não se teve tempo para se debater outras perspectivas educacionais para essas escolas. Assim sendo, a lógica de organização escolar apenas foi mantida.

Na ausência de mais estudos e pesquisas não podemos ainda mensurar o impacto da gestão compartilhada, a esse respeito podemos simplesmente fazer uma inferência: essas escolas que atende a população em Jataí seguem o mesmo modelo de organização das escolas da cidade, na segunda fase do ensino fundamental e ensino médio elas não possuem nem mesmo uma equipe gestora própria. Pelo fato dessa gestão ocorrer de forma itinerante, os seus gestores não participam do dia-a-dia da escola, ficando assim distantes dos assuntos de interesse da comunidade que ela atende. Não se esquecendo ainda que as atividades são norteadas por um PPP que não foi pensado a partir das peculiaridades camponesas.

No entanto, não há até o momento, fontes que nos permitam perceber se a implantação da gestão compartilhada tem sido avaliada, e se nessa avaliação apareçam elementos que nos permitam afirmar que possa ser uma das preocupações desse novo modelo de gestão, uma organização escolar vinculada à problemática da vida do camponês. É importante assinalar que, por ser um novo modelo de gestão, é possível que possa figurar no futuro entre os debates da gestão compartilhada, a preocupação de organizar as escolas rurais de acordo com a realidade do campesinato.

\section{CONSIDERAÇÕES FINAIS}

Próximo das linhas finais deste texto podemos fazer algumas considerações a respeito da realidade educacional das escolas localizadas no campo em Jataí. Amparados pelos estudos acadêmicos de Silva et.al (2010) e Leal e Carvalho (2009), sabemos que as escolas que atendem a população camponesa em Jataí são apenas escolas da cidade inseridas no meio rural. 
Sabemos também que essas escolas são administradas de forma conjunta pelo sistema de ensino Municipal e Estadual por meio da gestão compartilhada. Porém, não possuímos na atualidade nenhum dado que nos possibilite mensurar quais são os efeitos dessa nova forma de gestão para essa realidade escolar.

Assim, traçamos um panorama da realidade educacional das escolas localizadas no campo no município de Jataí, porém, conhecer essa realidade não resolve a problema do atendimento educacional dessa população. Na busca pela transformação dessa realidade, acreditamos que é por meio de novos estudos acadêmicos que poderemos encontrar os caminhos para uma organização escolar que tenha sentido aos anseios da população camponesa Jataiense. Por isso novos estudos que se dediquem a essa temática se faz necessários. Além disso, faz-se necessário ainda abrir canais de diálogo entre as Universidades e SME/SEE no sentido de estreitar os conhecimentos gerados nos centros acadêmicos e instituições escolares, a fim de experiênciar novas possibilidades educacionais para as regiões e populações rurais.

\section{REFERÊNCIAS BIBLIOGRÁFICAS}

\section{REFERÊNCIAS BIBLIOGRÁFICAS}

DIAS, Mariza Souza. Pequenos produtores Rurais de Jataí: caracterização e relevância. UFG, 2008. Monografia (Graduação em geografia) - Universidade Federal de Goiás.

FREIRE, Paulo. Pedagogia do Oprimido, $17^{\circ}$ ed. Rio de Janeiro, Paz e terra. 1987.

LEAL, Cátia Assis Almeida. Arapuca Armada: ação coletiva e práticas educativas na modernização agrícola do sudoeste goiano. Goiânia, 2006. Tese de Doutorado (Doutorado em Educação) - Faculdade de Educação, Universidade Federal de Goiás, 2006.

LEAL, Cátia Regina Assis Almeida. CARVALHO, Tatielle Goulart. Perspectivas de desenvolvimento do Sudoeste Goiano: Repensando a Educação Física Escolar e sua Prática Pedagógica no Contexto da Educação Rural. Jataí, Relatório Parcial (PROLICEN) Universidade Federal de Goiás.

LEAL, Cátia Regina Assis Almeida. CARVALHO, Tatielle Goulart. Perspectivas de desenvolvimento do Sudoeste Goiano: Repensando a Educação Física Escolar e sua Prática 
Pedagógica no Contexto da Educação Rural. Jataí, 2010. Relatório Final (PROLICEN) Universidade Federal de Goiás.

OLIVEIRA, Breno Louzada Castro de. Educação e Ruralidades Jataienses. Goiânia, 2004. Dissertação de Mestrado (Mestrado em Educação) - Faculdade de Educação, Universidade Federal de Goiás, 2004.

PESSOA, Jadir de Morais. Artigo 28 sem rodeios: a educação rural na nova ldb. fragmentos de cultura, Goiânia, n.7 (28), p. 149-158, 1997.

PESSOA, Jadir de Moraes (org). Educação e ruralidades. Goiânia : editora UFG, 2007.

SILVA. João Paulo dos Santos et.al. Currículo: escola rural Jataiense. In: $7^{\circ}$ Semana de Licenciatura, Jataí, GO. Junho - 2010.

SOUZA, Joana Dark’s de. A intervenção no Colégio feliz: Gestão compartilhada. Goiânia: FE/UFG, 2009. Trabalho de conclusão de curso (especialização em Gestão Escolar) Faculdade de Educação, Universidade Federal de Goiás, 2009. 